\title{
El rol del capital social en los procesos de desarrollo local. Límites y alcance en grupos indígenas
}

\author{
Laura Mota Díaz \\ EdUARdo A. SANDOVAl Forero*
}

\begin{abstract}
There is the idea - encouraged by international organisations and the State - that the social capital contributes to the strengthening of democracy, equality, participation culture and therefore, development. Nevertheless, it is necessary to ponder the concept of indigenous social capital which embraces three elements: a) the capacity of economical and cultural survival, $b$ ) the possibility of establishing an organisation structure, fighting mechanisms, resistance and adjustment to a society and to a national project in a situation of subordination and high vulnerability; and c) the effects that the hegemonic structures have on the weakening of the indigenous social capital and its transformation into new expressions of social capital or even its loss and absence.
\end{abstract}

Keywords: social capital, local development, poverty, social policy, indigenous population.

\section{Resumen}

Hay una idea, promovida por los organismos internacionales y el Estado, en torno a que el capital social contribuirá al fortalecimiento de la democracia, a la equidad, a la cultura de participación y, consiguientemente, al desarrollo. No obstante, es necesario detenernos en la noción de capital social indígena, que pasa por tres elementos: a) la capacidad para sobrevivir económica y culturalmente; $b$ ) la posibilidad de conformar organización, mecanismos de lucha, resistencia y ajuste a una sociedad y a un proyecto nacional, en medio de una relación de subordinación y vulnerabilidad alta, y c) los efectos que las estructuras hegemónicas tienen en el debilitamiento del capital social indígena y su transformación en nuevas expresiones de capital social o incluso en su pérdida y ausencia.

Palabras clave: capital social, desarrollo local, pobreza, política social, población indígena.

* Centro de Investigación en Ciencias Políticas y Administración Pública, Facultad de Ciencias Políticas y Administración Pública, Universidad Autónoma del Estado de México. Correos-e: lmd@politicas.uaemex.mx y esandovl@uaemex.mx. 


\section{Introducción}

Desde los años ochenta, en toda América Latina se han implantado diversas reformas tendentes a conciliar el desarrollo económico con el desarrollo social. Las reflexiones más frecuentes que anteceden a este proceso se sitúan en el origen de los problemas de gobernabilidad, en la propia complejidad del ejercicio de un poder omnipresente, pero también, y fundamentalmente, en la falta de legitimidad que implica, de cara a los ciudadanos, la incapacidad para llevar a buen término los programas políticos y para propiciar un crecimiento económico y por tanto el bienestar de la sociedad. En este proceso, diversas han sido las fórmulas aplicadas, sin que ello contribuya a aminorar los fenómenos de pobreza, marginación, desigualdad y exclusión que afectan a una gran parte de los habitantes de la región.

Las llamadas reformas de primera generación, cuyo origen se derivó del Consenso de Washington, y que se sintetizaron como menos Estado y más mercado, se orientaron fundamentalmente a la apertura y estabilización económica, como respuesta a las condiciones impuestas por la globalización económica y financiera. Mientras tanto, en el ámbito de la función del Estado, se orientaron a la reducción del aparato burocrático.

En su desarrollo, dichas reformas mostraron su ineficiencia para lograr -como se esperaba- una reducción significativa de la pobreza, y en forma casi automática, una mejora en la distribución del ingreso; tampoco dieron respuesta al problema central de cómo generar en el Estado una nueva institucionalidad que promoviera la mayor equidad y el desarrollo democrático. Fue entonces cuando se plantearon las reformas de segunda generación, que, en esencia, se orientaron a la redefinición de la relación Estado-sociedad con el objetivo de establecer condiciones de gobernabilidad democrática que garantizaran la relegitimación del Estado como un medio para superar la crisis social.

Tales reformas se encaminaron a la promoción de la descentralización, la participación y el control ciudadano sobre la gestión de los gobiernos, de acuerdo con diversos objetivos, entre ellos: lograr un crecimiento económico sostenido, reducir los niveles de pobreza, mejorar el desempeño de las instituciones, reformar el sistema de justicia, así como los de salud y educación, y recuperar la importancia de los espacios locales.

En este contexto, el debate de los años noventa sobre el desarrollo -concebido a partir de entonces como desarrollo humano- 
puso énfasis en los recursos humanos y en los procesos políticos y sociales que se construyen a su alrededor, a partir del postulado de que los seres humanos no son sólo un medio del desarrollo sino su fin último. En tanto, la corriente del neoinstitucionalismo argumentó que las instituciones y las organizaciones determinan en gran medida el desempeño económico y social.

Fue en este debate donde los conceptos de capital humano y capital social se tornaron relevantes y se incorporaron a las políticas públicas, en el supuesto de que su promoción y ampliación contribuyen a superar el subdesarrollo y permiten la integración al modelo global. Por un lado, se planteó que el capital humano es una vía para alcanzar productividad, progreso tecnológico y competitividad en los escenarios económicos actuales. Por otro lado, se estableció que el capital social contribuye al fortalecimiento de la democracia, al logro de la equidad y a la cultura de participación, elementos que, en conjunto, conducirán al ansiado desarrollo.

A pesar de los argumentos y los méritos que se le atribuyen al capital social, existen muchas imprecisiones en su definición y operación, así como en su supuesta contribución a la reducción de la pobreza y al fortalecimiento de la participación y la democracia, pues hay espacios que han sido poco explorados, como el de las comunidades indígenas, que hoy día siguen siendo las más marginadas, pobres y excluidas y que, paradójicamente, son las poblaciones que poseen un mayor potencial para el capital social.

El objetivo en este artículo es discutir, en una primera parte, la noción de capital social, sus principales postulados y la contribución que se le atribuye en los procesos de desarrollo. En una segunda parte, la discusión sobre el capital social se traslada al ámbito del desarrollo local, especialmente hacia los municipios y comunidades con población indígena, para mostrar los límites que encuentra para la promoción de la participación social y el potenciamiento ${ }^{1}$ de las comunidades.

Partimos de la hipótesis de que la noción de capital social indígena pasa por un balance de tres elementos:

1 "El potenciamiento se entiende como la ampliación de la capacidad y las opciones de la gente; en otras palabras, significa que en el curso de su vida cotidiana la gente puede participar en la adopción de decisiones que afecten a sus vidas o apoyarlas, sin estar sujetos a hambre, pobreza y privación" (PNUD, 1998). 
a) La habilidad para sobrevivir económica y culturalmente.

b) La capacidad de propiciar mecanismos de lucha, resistencia y ajuste a una sociedad y a un proyecto nacional, en medio de una relación de subordinación y alta vulnerabilidad.

c) Los efectos que las estructuras hegemónicas tienen en el debilitamiento del capital social indígena y su transformación en nuevas expresiones de capital social o incluso en su pérdida y ausencia.

\section{Orígenes y desarrollo del concepto}

Aunque la discusión teórica y la utilización del concepto de capital social en las políticas públicas orientadas a la superación de la pobreza son relativamente recientes, podemos afirmar que hay raíces históricas del término en algunos escritos del siglo XIX. Por ejemplo, Alexis de Tocqueville ([1840] en Fukuyama, 2000: 31), en su Democracia en América, observó que, a diferencia de Francia, América poseía un arte de asociación valioso, y aunque no aludía explícitamente a capital social, sí hacía referencia a la noción de voluntariado. Émile Durkheim ([1893] en Toledo, 2004: 155), en La división del trabajo social, planteó que la conciencia colectiva es la base para entender los procesos que constituyen la cohesión social. Según este autor, la conciencia colectiva comprende la totalidad de las representaciones que los individuos se hacen sobre su vida misma en sociedad y, por tanto, también sobre las relaciones entre individuos. En la obra de Karl Marx ([1894] en Toledo, 2004: 175), cuando aludía a las relaciones sociales de producción, quedaba implícito el hecho de que las sociedades están cruzadas por relaciones de grupos que se sitúan en diferentes posiciones estructurales dentro del proceso productivo.

Ya en las primeras décadas del siglo xx, Lydia Judson Hanifan ([1920] en Ostrom y Ahn, 2003: 159), se refirió al papel de las comunidades en la satisfacción de las necesidades sociales de los individuos; destacaba la existencia de elementos como la buena voluntad, el compañerismo, la empatía y las relaciones sociales entre individuos y familias, que conforman una unidad social (Ostrom y Ahn, 2003: 159).

En gran parte de la literatura reciente sobre el concepto y desarrollo del capital social pueden apreciarse tres vertientes que le otorgan a este concepto un carácter multidisciplinario: la antropológica, la sociológica y la económica. 


\subsection{La vertiente antropológica}

Diversos estudios de corte antropológico y etnológico han analizado las relaciones de reciprocidad, confianza y solidaridad dentro de las comunidades rurales y urbanas para referirse al funcionamiento de los sistemas sociales comunitarios. Uno de los primeros trabajos fue el que desarrolló Marcel Mauss ([1996], en Durston, 2000: 9), en su Ensayo sobre el Don, en el que hace referencia al concepto de reciprocidad, a la que identifica como un principio regidor de las relaciones institucionales formales e informales en la comunidad. A partir de ello describe cómo en las sociedades premercantiles operaban sistemas de intercambio basados en obsequios, que funcionaban como una compensación de carácter obligatorio recibida por un favor y que consistía en objetos, ayuda, o bien, otro favor. Tales relaciones -de acuerdo con Gauss- sucedían en todos los ámbitos e instituciones de la vida humana: religioso, político, jurídico, familiar y económico (citado en Durston, 2000: 9). Desde luego, ese comportamiento se deriva de factores culturales y actualmente se percibe todavía en comunidades con presencia indígena.

En la década de los sesenta, otros trabajos antropológicos trataron el concepto de reciprocidad: los de Raymond Firth (1961), quien basado en su concepto de organización social, mostró cómo a partir de relaciones sociales regulares se generan instituciones y estructuras sociales; y los de George Foster (1961), particularmente en sus conocidos escritos Los contratos diádicos, a los que se refiere como base de la interacción entre pares y redes de relaciones recíprocas.

A partir de los estudios descritos podemos decir que Mauss, Firth y Foster fueron precursores de la introducción de uno de los términos que posteriormente daría forma al concepto de capital social: la reciprocidad.

En los años setenta, diversos trabajos antropológicos analizaron el tema de la migración campo-ciudad, donde destacaban las condiciones marginales que adquirían los migrantes en las urbes. Así, emplearon los términos de confianza y solidaridad para referirse al funcionamiento de las redes sociales que se conformaban como producto de las estrategias de sobrevivencia desplegadas por los pobres en las ciudades. ${ }^{2}$

${ }^{2}$ En México destacan los trabajos de Larissa Adler, Cómo sobreviven los marginados (1975), y de Lourdes Arizpe, Indígenas en la Ciudad de México. El caso de las "Marías" (1979). Un antecedente importante, que vale la pena mencionar, es el texto 
Hasta aquí podemos observar la existencia de cuatro elementos que dieron forma a los posteriores desarrollos teóricos del capital social: reciprocidad, confianza, solidaridad y redes sociales.

\subsection{La vertiente sociológica}

La introducción del término, tal como se conoce en el debate contemporáneo, se debe a la sociología. Durante las décadas de los ochenta y los noventa, las investigaciones sociológicas se abocaron al análisis y redimensionamiento del capital social, al que calificaron como un recurso que, combinado con otros factores, produce ciertos beneficios y cuya base constituyen las relaciones sociales que se fundamentan en normas comúnmente aceptadas.

Entre los sociólogos más notables que estudian el concepto de capital social, destaca Pierre Bourdieu (1983: 78), quien lo define como "el agregado de los recursos reales o potenciales ligados a la posesión de una red durable de relaciones más o menos institucionalizadas de reconocimiento mutuo". De acuerdo con este autor, es dentro del contexto de las relaciones y redes sociales donde un actor puede movilizarse en beneficio propio. En su análisis, Bourdieu se refiere a las relaciones sociales desiguales como campos, y sostiene que éstos conforman los espacios de luchas donde los grupos intentan apropiarse de las posiciones dominantes para obtener los beneficios que trae aparejados el mismo campo. Este grupo de beneficios propios de un campo conforman los capitales que, según Pierre Bourdieu, adoptan tres formas esenciales: capital económico (constituido por rentas y fortunas), capital social (compuesto por las redes y relaciones sociales) y capital cultural (determinado por el grado de escolaridad y también por las prácticas). La preocupación de Bourdieu se concentró en evaluar la manera en que los tipos de capital se subordinan al capital económico y cómo interactúan con estructuras más amplias que producen desigualdades sociales (Baquero, 2001).

Otro autor que subraya en esta vertiente es James Coleman (1990), para quien el capital social son "los recursos estructurales que constituyen un activo de capital para el individuo y facilitan ciertas acciones de individuos que están adentro de esa estructura”. Según este autor, el capital social es productivo en la 
medida que posibilita el logro de ciertos fines que no serían alcanzables en su ausencia, y se presenta tanto en el plano individual como en el colectivo. En el primero tiene que ver con el grado de integración social de un individuo y su red de contactos sociales; implica relaciones, expectativas de reciprocidad y comportamientos confiables; mejora la efectividad privada, pero también conforma un bien colectivo (citado en Durston, 2000: 9). La atención de Coleman está dirigida a la importancia de las obligaciones mutuas, de las normas sociales y de las relaciones de confianza que revisten la vida social.

Tanto Bourdieu como Coleman se refieren al capital social como un atributo de grupos sociales, colectividades y comunidades teniendo en cuenta que el rol de las instituciones sociales en su establecimiento es importante. Por ello, puede decirse que ambos autores son los que expresaron por vez primera, y de forma relativamente detallada y completa, el concepto de capital social, pues los trabajos antropológicos que les antecedieron, si bien aportaron elementos para la construcción del concepto, no lo introdujeron en los términos actualmente conocidos.

A partir de los trabajos de Bourdieu y Coleman fue conformándose una gran cantidad de investigaciones teóricas y empíricas sobre el capital social y creció -especialmente entre los generadores de políticas- la atracción por el concepto. Uno de los estudiosos más citados en el debate reciente es Robert Putnam (1993: 67), para quien el capital social son los "rasgos de la organización social, tales como las redes, las normas y la confianza, que facilitan la acción y la cooperación para el mutuo beneficio”. A partir de su investigación sobre los gobiernos locales en Italia, Putnam estableció que dicho capital está constituido por el grado de confianza entre los actores sociales, las normas de comportamiento cívico practicadas y el nivel de asociatividad que caracteriza a la sociedad, todo lo cual fortalece la confianza social y alimenta, a su vez, las redes sociales que hacen posible esas diversas formas de participación ciudadana.

Puede decirse que los postulados de Putnam con relación al capital social configuran el punto de partida para que se considere actualmente un elemento importante en el desarrollo, ya que en sus trabajos este autor enfatiza en el hecho de que la eficiencia de la acción y el logro de ciertos objetivos de interés nacional están fuertemente influidos por la implicación de los ciudadanos en los asuntos que conciernen más bien a sus comunidades. Así, 
destaca el aspecto de la participación ciudadana y su promoción a partir de las redes sociales existentes.

Otro autor recurrente en los análisis teóricos del capital social es Alejandro Portes (Portes y Landolt, 1996). Señala que el capital social no es la única variable explicativa de los efectos benéficos que suelen atribuírsele, pues la posesión de recursos materiales es tanto o más relevante que el acceso a capital social; esto es, que si se tiene una red social recíproca y rica en capital social pero se carece de recursos económicos, difícilmente se logrará el éxito. Portes destaca que en el marco de las relaciones sociales, los efectos del capital social pueden ser tanto positivos como negativos.

\subsection{La vertiente económica}

En la perspectiva económica del capital social destaca Mark Granovetter (1985), para quien los actores económicos no son átomos aislados sino que sus interacciones económicas están inmersas en las relaciones, redes y estructuras sociales. La idea central de este postulado es que las relaciones sociales son activos económicos importantes de los individuos y de los grupos. De acuerdo con este autor, el comportamiento racional de las personas abarca no sólo objetivos económicos sino también la sociabilidad, la aprobación, el status y el poder; y, a la inversa, las relaciones sociales y la estructura social juegan un papel central en el comportamiento económico.

Desde el institucionalismo económico, Douglass North (1990) alude de modo implícito en la mayoría de sus escritos a la noción de capital social. En su opinión, las instituciones son conjuntos de normas y valores que facilitan la confianza entre los actores, pero son abstractas; mientras que las organizaciones son manifestaciones concretas de cooperación basadas en la confianza. En este caso, el autor destaca la importancia de las instituciones para el fomento del capital social, pero deja claro que las organizaciones son fundamentales, en tanto que en ellas se produce y reproduce la confianza y la reciprocidad.

Otro de los aportes económicos procede del estudio realizado por Stephen Knack y Philip Keefer (1997), quienes presentan evidencia, para un amplio conjunto de economías de mercado desarrolladas, de que el capital social, entendido a partir de la confianza y la cooperación cívica, constituye uno de los determinantes clave del desempeño económico. 
Las tres vertientes expuestas forman el marco teórico y el punto de partida de muchos de los trabajos desarrollados en la actualidad sobre capital social.

\subsection{Las definiciones contemporáneas}

En el debate contemporáneo, donde el centro del capital social es el de su contribución al desarrollo social, en la medida que puede aportar avances en la reducción de la pobreza y lograr la gobernabilidad democrática, destacan autores como John Durston (2000: 9-10), para quien el capital social constituye "un paradigma emergente rico en conceptos que corresponde a realidades sociales altamente relevantes para diseñar programas orientados a promover la participación social y superar la pobreza”. Según este autor, "el capital social es el contenido de ciertas relaciones y estructuras sociales, es decir, las actitudes de confianza que se dan en combinación con conductas de reciprocidad y cooperación" (Durston, 2002: 15).

Francis Fukuyama (2000: 28) afirma que el capital social puede ser definido como un conjunto de valores o normas informales, comunes a los miembros de un grupo, que permiten la cooperación entre ellos. Sin embargo, subraya que la existencia pura y simple de valores comunes no produce capital social, pues se requieren virtudes como honestidad, cumplimiento de obligaciones y reciprocidad.

Otros autores, citados por Kliksberg y Tomassini (2000: 29), que destacan las potencialidades del capital social para contribuir al desarrollo mediante la cooperación y la participación social son: Kenneth Newton, quien sostiene que el capital social puede ser visto como un fenómeno subjetivo, compuesto de valores y actitudes que influyen en cómo las personas se relacionan entre sí. Incluye confianza, normas de reciprocidad, actitudes y valores que ayudan a las personas a trascender relaciones conflictivas y competitivas para establecer relaciones de cooperación y ayuda mutua. Otro investigador es Stephan Baas, para quien el capital social tiene que ver con la cohesión social, con identificar las formas de gobierno, con expresiones culturales y comportamientos sociales que le dan a la sociedad mayor afinidad y hacen de ella algo más que una suma de individuos. En tanto, James Joseph lo percibe como un vasto conjunto de ideas, ideales, instituciones y arreglos sociales, por medio de los cuales las personas encuentran su voz y movilizan sus energías particu- 
lares para causas públicas. Finalmente, Bullen y Onyx lo ven como redes sociales basadas en principios de confianza, reciprocidad y normas de acción.

Destaca en años recientes la perspectiva de los organismos internacionales que, en ese afán por encontrar respuestas a los múltiples problemas de desigualdad, exclusión y pobreza que privan en los llamados países en desarrollo, se han dado a la tarea de fomentar la utilización del capital social en los proyectos de desarrollo. El Banco Interamericano de Desarrollo (BID) se coloca como una de las instituciones líderes en esta visión. Así, ese organismo define el capital social como las variadas formas de organización social que han existido a lo largo de la historia y que han sido utilizadas por generaciones para movilizar recursos y atender fines de orden social, económico y político. Incluye instituciones comunitarias, autoridades tradicionales, redes de parentesco y vecinos, organizaciones religiosas de servicio, y otras formas de asociaciones voluntarias y de autoayuda (BID, 2001).

Para el Banco Mundial (BM) (2001a), el capital social se refiere a las instituciones, relaciones y normas que conforman la calidad y cantidad de interacciones sociales de una sociedad. No es sólo la suma de las instituciones que configuran una sociedad, sino la materia que las mantiene juntas.

En todas las definiciones reseñadas podemos encontrar elementos de consenso en torno al concepto de capital social:

a) En lo general, es concebido como el conjunto de normas de confianza, valores, actitudes y redes entre personas e instituciones en una sociedad que definen el grado de asociatividad entre los diferentes actores sociales y facilitan acciones colectivas.

b) El capital social existe en el plano colectivo y en el individual.

c) Su utilización genera beneficios tanto individuales como colectivos.

d) Es útil para el diseño de políticas sociales.

Sin embargo, a pesar de ser un concepto que ha ido perfilándose durante varias décadas, actualmente la noción de capital social se encuentra aún en formación y discusión en su aplicación concreta al desarrollo, por el hecho de que las sociedades han experimentado una cantidad de transformaciones que las han llevado a una mayor complejidad, tanto en sus instituciones como en sus organizaciones y relaciones sociales. 
Por lo pronto, asumimos que la reciprocidad, cooperación y confianza son elementos que dan contenido al capital social, y que éstos forman un importante recurso sociocultural en cualquier grupo humano; aunque no siempre puede producir efectos benéficos, ya que el capital social existe también en un conjunto de acciones individuales o colectivas que no necesariamente se orientan al bien común. A esto agregamos el hecho de que tal recurso se transforma en capital sólo cuando existen oportunidades que permitan la producción de beneficios.

\section{Formas y tipos de capital social}

Los desarrollos teóricos actuales han permitido ampliar la noción de capital social, al grado que puede distinguirse una tipología.

Durston (2000: 21) plantea dos tipos de capital social: el individual y el comunitario. El primero se manifiesta principalmente en las relaciones sociales con contenido de confianza y reciprocidad que posee la persona, y se extiende mediante redes egocentradas. En este caso no se persiguen objetivos comunes para el beneficio de una colectividad, sino más bien el beneficio de una persona usando las relaciones sociales que ha establecido con otras. En cambio, el segundo se expresa en instituciones complejas con contenido de cooperación y gestión que sí persiguen beneficios para la colectividad.

En el mismo sentido, Deepa Narayan (1999) distingue dos tipos de capital social: uno que genera lazos de unión entre los miembros de una misma comunidad, al que denomina capital social horizontal, y otro que genera sinergia entre grupos disímiles, al que llama capital social vertical. El primero se limita a potenciar el bienestar de los miembros pertenecientes a una misma comunidad, mientras que el segundo es el tipo de capital que abre oportunidades económicas a quienes pertenecen a los grupos menos poderosos o excluidos.

Grootaert y Van Bastelaer (2001) distinguen tres dimensiones del capital social: su alcance (o unidad de observación) en niveles micro, meso y macro; sus formas (o manifestaciones), que pueden ser estructurales o cognitivas, y los canales por medio de los cuales el capital social afecta el desarrollo, como la diseminación de información valiosa y la toma de decisiones colectivas mutuamente provechosas.

Para Molinas (2002), el capital social puede distinguirse en dos formas: 
1. Según la relación de los involucrados, y agrupa tres tipos: a) aglutinador, por las relaciones que se establecen entre familiares, vecinos y amigos; $b$ ) de puente, conforme a las conexiones horizontales entre personas con características similares, independientemente de lo bien que se conozcan y c) Vinculante, por la capacidad de movilizar recursos, ideas e información más allá de la comunidad por medio de interacciones con personas en posición de poder.

2. Según su forma, agrupa dos tipos: a) cognitivo, según las normas, valores, confianza, actitudes y creencias compartidas; es decir, se trata de un capital subjetivo e intangible, y $b$ ) estructural, se refiere principalmente a organizaciones -formales e informales- y a redes organizacionales y asociativas.

Cabe destacar algunas de sus especificidades con relación a otros tipos de capital, así como algunas limitaciones del capital social para mejorar las condiciones de vida de las personas. Entre las características peculiares del capital social, podemos citar lo siguiente: $a$ ) a diferencia del capital físico, que se deprecia con el uso, el capital social se acrecienta con su uso y se deprecia sólo si no se lo usa (Putnam, 1993); b) a diferencia de inversiones en capital humano ( $\mathrm{y}$ en muchos casos de los físicos), los resultados en el aumento de productividad del capital social pueden verse en un plazo muy corto; $c$ ) el capital social no es la propiedad privada de ninguna de las personas que se benefician de él, y $d$ ) el capital social no puede ser prestado internacionalmente, debe producirse localmente.

De acuerdo con Grootaert y Van Bastelaer (2001), es difícil medir el capital social. No existe aún un consenso sobre cuál es el mejor indicador para medirlo, como lo hay en relación con el capital humano. No obstante, pueden identificarse tres tipos de indicadores principales: $a$ ) membresía en asociaciones locales y redes: es un indicador de capital social estructural; $b$ ) indicadores de acción colectiva: indicadores de cohesión social que se ven reflejados en la medida que se obtiene la provisión de servicios con base en la acción colectiva de un grupo de individuos, y c) indicadores de confianza y adherencia a normas: indicadores de capital social cognitivo.

En estos avances del concepto, es posible observar el surgimiento paralelo de una corriente crítica del capital social que se sintetiza en los siguientes puntos: 
a) Que el concepto es ambiguo y ambicioso y como tal no constituye una teoría.

b) Que se trata de un discurso que le pone etiquetas nuevas a ideas viejas.

c) Que en sentido estricto, no constituye una forma de capital.

d) Que es intangible, lo que dificulta su medición.

e) Que no hay una elaboración metodológica para saber cómo afecta cada forma de capital social al desempeño económico y político.

f) Que presenta un lado negativo, en tanto que es un atributo de organizaciones delictivas, lo que, por supuesto, ya no garantiza el bien común.

A partir de estas críticas y de otros elementos que más adelante examinamos, el planteamiento de que el capital social puede ayudar a superar los problemas de pobreza y a lograr la gobernabilidad democrática es cuestionable.

\section{Capital social, pobreza y desarrollo}

En los últimos cincuenta años, los enfoques sobre la pobreza y el desarrollo han venido evolucionando a medida que las sociedades se han vuelto más complejas por los avances científicos y tecnológicos; pero también en la medida que la pobreza y la desigualdad se han profundizado en algunas regiones del planeta, como es el caso de América Latina.

Por varias décadas predominó la noción de que el crecimiento económico llevaría por sí solo al desarrollo; tanto así que las acciones del Estado se abocaron a invertir en capital físico e infraestructura. Con esta idea, en América Latina la industrialización se convirtió en la estrategia más importante del desarrollo donde la década de los cuarenta hasta la de los setenta. Para entonces, la pobreza se concebía como la insuficiencia de ingresos económicos para satisfacer necesidades esenciales de alimentación (Mota, 2002: 47). Según esta visión, los pobres eran aquellos que no tenían los recursos monetarios suficientes para adquirir una canasta básica de alimentación (Mota, 2002: 47).

En la década de los setenta, cuando se hicieron evidentes las mayores desigualdades regionales, la marginalidad urbana y la pobreza rural como consecuencia de los efectos que produjo la localización industrial, comenzó a reflexionarse en el sentido de que no era suficiente el crecimiento para lograr el desarrollo; a partir 
de esto se consideró que era importante dar atención a variables como la salud y la educación, que, para entonces, se constituían como graves problemas sociales que limitaban el acceso al empleo y, por consiguiente, al ingreso, lo que generaba mayor pobreza. Durante esa década se consideró que los pobres eran aquellos cuyos ingresos resultaban insuficientes para satisfacer necesidades de alimentación y que además carecían de satisfactores básicos como la salud, la educación, la vivienda y servicios de agua, luz y drenaje, entre otros elementos.

Durante todos esos años, las acciones del desarrollo fueron competencia exclusiva del Estado; a éste le correspondía diseñar políticas y programas, así como destinar recursos y decidir sobre lo que consideraba prioritario. Pero la ineficiencia mostrada hizo que a fines de los setenta el mito del Estado se derrumbara y diera paso a una nueva discusión sobre el enfoque del desarrollo, a partir de lo cual se planteó la necesidad del cambio de modelo económico y la reforma del Estado.

Así, la década de los ochenta se orientó a la puesta en práctica de los planteamientos económicos neoliberales y de transformación del Estado. En ese entonces se inició el proceso de democratización en América Latina y resurgió el tercer sector, que obligó a los organismos internacionales -impulsores de la reforma- y al propio Estado a orientar sus acciones en favor de la participación social y la descentralización en el proceso de políticas públicas.

No obstante, al terminar la década de los ochenta el sentimiento de retroceso en lo tocante a las condiciones de vida era innegable, pues la expresión más dramática del ajuste y de las secuelas del pago de la deuda fueron precisamente la pobreza y la desigualdad, lo que generó un sentimiento de que todavía faltaba mucho por hacer y de que había que seguir replanteando las acciones del desarrollo.

Así, en los siguientes diez años la idea del mercado se afianzó más en el enfoque del desarrollo, pero también cobró importancia la idea de la democratización como un elemento indispensable. Se trataba ahora de aumentar la inserción de los países en los mercados mundiales, enfatizar la importancia de los mecanismos de mercado en la asignación de recursos y atribuir un nuevo papel al Estado como regulador y supervisor antes que como productor y oferente de recursos. Esa profunda transformación se tornaba urgente en una situación caracterizada por interdependencias crecientes de las economías nacionales, pro- 
gresiva apertura comercial, integración de los mercados financieros mundiales y acelerado cambio tecnológico.

Con relación al tema de la democratización, hacia 1993 los informes mundiales de desarrollo humano llegaron a la conclusión de que el desarrollo sólo es posible y sostenible en la medida que la sociedad o los grupos sociales sean los diseñadores y actores de ese proceso. De este modo se planteó que la participación social es un elemento importante tanto para la democracia como para la equidad (Mota, 2002: 49-59).

A mediados de los noventa, cuando se verificó la Cumbre de Copenhague, la pobreza y el desarrollo se colocaron como temas prioritarios en las agendas de los organismos internacionales. En la cumbre se afirmó que el mercado por sí solo no sería la fórmula para erradicar la pobreza, ni lograría la equidad ni la igualdad necesarias para el verdadero desarrollo; se enfatizó así la importancia de las personas como individuos y como actores capaces de hacer el cambio en sus comunidades, con lo que se propuso sustituir el enfoque paliativo por el del desarrollo de capacidades. En estos términos, el objetivo de la erradicación de la pobreza se precisaba como una forma clara de poner en práctica los derechos sociales y económicos señalados en la Declaración Universal de los Derechos Humanos (Unesco, 2001).

Así, el concepto de pobreza adquiere también otras dimensiones. Ya no se considera pobre sólo a aquel que carece de ingresos suficientes para satisfacer necesidades básicas o al que carece de servicios básicos indispensables para llevar una vida digna, tal como se le definió en décadas anteriores, y aún en los inicios de los noventa, cuando el Banco Mundial todavía definía la pobreza como la imposibilidad de alcanzar un nivel de vida mínimo, refiriéndose más a la pobreza en sentido absoluto, a la que conceptuó como la insatisfacción de necesidades básicas según un patrón mínimo basado en el escaso nivel de ingreso, o bien, como la insatisfacción en el acceso a servicios básicos, que incluyen educación básica, salud, alimentación y vivienda (Banco Mundial, 1990).

A partir de la Cumbre de Copenhague, y con base en los planteamientos de Amartya Sen en torno a que la pobreza significa carencia de derechos, se consideró que los pobres son aquellos que:

[...] no sólo carecen de ingresos, sino también de las atenciones sanitarias mínimas, de la posibilidad de acceso a la educación e incluso de agua. Carecen de oportunidades, viven aislados y sin ningún poder. A menudo 
están marginados por cuestiones de etnia, casta, geografía, género o discapacidad. Y sobre todo, no pueden ser oídos en los sitios donde se toman las decisiones que afectan a sus vidas (UNESCO, 2001: 12).

Con este enfoque surgió una cantidad de conceptos en torno a la pobreza. Por ejemplo, el Programa de Naciones Unidas para el Desarrollo (PNUD) introdujo varios indicadores socioeconómicos en su definición sobre el desarrollo humano ${ }^{3}$ y la pobreza, al asentar que ésta tiene muchos rostros y abarca más que un nivel bajo de ingresos, pues refleja también mala salud y educación, la privación de conocimientos y comunicaciones, la incapacidad para ejercer derechos humanos y políticos, y la falta de dignidad, confianza y respeto por sí mismo (PNUD, 1997).

Paul Spicker (1999) propuso once posibles formas de interpretar la pobreza: necesidad, estándar de vida, insuficiencia de recursos, carencia de seguridad básica, falta de titularidades, privación múltiple, exclusión, desigualdad, clase, dependencia y padecimiento inaceptable.

A partir de los nuevos enfoques de pobreza, los términos de exclusión social y vulnerabilidad cobran vigencia y significan los retos mediante políticas de ataque a la pobreza. En este entendido se plantea que tales políticas deben favorecer la equidad, la participación ciudadana y la justicia social.

No obstante todos estos replanteamientos, la pobreza y la desigualdad continúan siendo graves problemas, pues la consolidación de la democracia, la equidad y la justicia social son anhelos aún no alcanzados en los países en vías de desarrollo, en los que las estructuras políticas constituyen un enorme obstáculo para estos alcances. Por tal razón, en los inicios del actual siglo se mantiene vigente la discusión en torno al desarrollo y la pobreza, centrada en los principios de equidad y democracia pero ahora con un enfoque hacia el fortalecimiento del capital humano y particularmente del capital social.

Cabe decir que desde 1996, los informes de desarrollo humano comienzan a utilizar el concepto de capital social para mostrar que los procesos económicos son sostenibles y dinámicos, no sólo en la medida que hay capital humano y financiero, pues reconocen que no es suficiente aumentar las capacidades perso-

${ }^{3}$ Desde que se publicó el primer Informe sobre desarrollo humano en 1990, se ha presentado el Índice de Desarrollo Humano (IDH) como una medición compuesta del tema. A partir de entonces se han implantado tres complementarios: el Índice de Pobreza Humana (IPH), Índice de desarrollo Relativo al Género (IDG) e Índice de Potenciación de Género (IPG) (PNUD, 2001). 
nales de los individuos si no hay un conjunto de tramas sociales que hagan que esas capacidades puedan efectivamente ponerse en juego. Desde entonces, el capital social forma parte de las condiciones centrales del desarrollo humano, pero adquiere mayor importancia al finalizar la década de los noventa y actualmente se mantiene vigente en los debates sobre el desarrollo. Según esta perspectiva, las personas, las familias y los grupos constituyen capital social por excelencia y representan una fuente potencial para el desarrollo social y humano.

El desarrollo humano entraña más que el simple aumento o disminución del ingreso nacional. Significa crear un entorno en el que las personas puedan hacer plenamente realidad sus posibilidades y vivir en forma productiva y creadora de acuerdo con sus necesidades e intereses. Los pueblos son la verdadera riqueza de las naciones y por ende, el desarrollo consiste en la ampliación de las opciones que ellos tienen para vivir de acuerdo con sus valores (PNUD, 2001: 1).

Junto a esta nueva concepción del desarrollo humano, los derechos humanos comparten una visión común en la medida que ambos plantean como objetivo la libertad humana, la cual resulta vital para el desarrollo de las capacidades y el ejercicio de los derechos.

En este sentido, la actual discusión plantea que el cumplimiento de derechos económicos, sociales y culturales permite avanzar hacia una mayor igualdad de oportunidades, tanto para tener acceso al bienestar como para afirmar la diferencia en el campo de la identidad. Se sostiene, así, que el desarrollo en el ejercicio efectivo de estos derechos debe complementarse con nuevas formas de ciudadanía, vinculadas con el acceso al intercambio mediático y la mayor participación de la sociedad.

Hay que decir que la ciudadanía ha sido entendida desde los orígenes del Estado de derecho como la posesión y el ejercicio de derechos inalienables por parte de los sujetos que integran la sociedad, y la obligación de cumplir deberes y respetar los derechos de los demás. ${ }^{4}$ Tales derechos comprenden los de autonomía individual frente al poder del Estado y de participación en las decisiones públicas, además de los derechos económicos, so-

${ }^{4}$ La ciudadanía, además, puede entenderse no sólo como el conjunto de instituciones y reglas que existen en una sociedad, sino también como las disposiciones a usar esas reglas en determinados sentidos, lo que implica el fortalecimiento de la sociedad a partir de la democracia (Durston y Miranda, 2001). 
ciales y culturales que responden a los valores de igualdad, solidaridad y no discriminación. ${ }^{5}$

Así, en el debate reciente se plantea como hipótesis que una distribución más justa en el ejercicio de la ciudadanía permite que los sectores excluidos tengan mayor presencia en las decisiones políticas y da más viabilidad al pleno ejercicio de los derechos sociales y culturales, lo cual redunda en un mayor bienestar social y mejor calidad de vida (Cepal, 2000a: 302). La ciudadanía, entonces, se percibe no sólo como una condición de libertad privada y de derechos políticos básicos, sino también como una condición que atañe a la calidad de vida de todos aquellos que forman parte de la sociedad. En este supuesto:

El ciudadano deja de ser un mero depositario de derechos promovidos por el Estado de Derecho o el Estado Social, para convertirse en un sujeto que, a partir de lo que los derechos le permiten, busca participar en ámbitos de "empoderamiento" (empowerment) que va definiendo según su capacidad de gestión y también según su evaluación instrumental de cuál es el más propicio para la demanda que quiere gestionar (Hopenhayn, 2001: 119).

Según este planteamiento, en la medida que la sociedad sea más capaz de moldear -dentro de ciertos límites- el funcionamiento de los sistemas, lo será más para establecer espacios para la propia realización de necesidades y aspiraciones subjetivas. Esto explica el uso del término "más sociedad" o "sociedad más fuerte", puesto que se trata precisamente de pensar cómo una sociedad, en las actuales condiciones históricas, es capaz de aumentar su capacidad de autodeterminación.

En estos términos se enmarca el actual discurso en torno a la lucha contra la pobreza y el desarrollo, pues se entiende ahora que "la pobreza no es sólo un problema de falta de ingresos o de desarrollo humano: pobreza es también vulnerabilidad e incapacidad de hacerse oír, falta de poder y de representación" (Banco Mundial, 2001b: 14).

Conforme a esta visión, se plantea que el ciudadano es el actor participante, en tanto que el pobre representa al inmóvil social, pues por su misma condición carece de todas las oportunidades para participar de manera activa en asuntos que tienen

${ }^{5}$ Entre estos derechos se han reconocido y consagrado los derechos al trabajo, a un nivel de vida adecuado, a la salud, a la alimentación, el vestido, la vivienda, la educación y la seguridad social, entre otros (Cepal, 2001). 
que ver con su calidad de vida, no sólo en el sentido material sino también en el simbólico. ${ }^{6}$ Por ello se concluye que:

La manera de hacer frente a esta complejidad es el potenciamiento y la participación -local, nacional e internacional. Los gobiernos nacionales deben dar cuenta completa a la ciudadanía acerca del camino del desarrollo que están siguiendo. Los mecanismos de participación pueden ofrecer a los hombres y mujeres una oportunidad de expresar su opinión, especialmente cuando se trata de los pobres y de los segmentos excluidos de la sociedad (Banco Mundial, 2001b: 14).

Con base en estos planteamientos se postula al capital social como la estrategia para superar la pobreza, fortalecer la participación ciudadana y lograr la equidad, ya que desde distintas perspectivas se le ve como la oportunidad para fortalecer las capacidades de la sociedad civil. Así, la recomendación es reforzar el capital social de los pobres a partir de la implantación de acciones que fortalezcan su capacidad de influir en las políticas estatales y nacionales y vincular las organizaciones locales a organizaciones más amplias.

Para promover la ciudadanía en un sentido más republicano, los Estados y sistemas políticos deben ser capaces de absorber y reflejar las nuevas prácticas de los movimientos sociales y combinar las políticas públicas con el capital social que la propia sociedad a través de sus organizaciones va forjando (Cepal, 2000a: 803).

En 1999, el "desafío de la inclusión” dio origen al Marco Integral del Desarrollo, cuyo acento se sitúa tanto en la consideración de elementos macroeconómicos como en la necesidad de establecer vínculos con estrechas relaciones de colaboración entre organismos multilaterales de desarrollo, gobiernos, sociedad civil y sector privado. Se destaca que la participación de la sociedad civil en los proyectos y programas de desarrollo conduce a mejores resultados en su diseño y ejecución (Stein, 2003: 30).

En este sentido, el BID (2001) sostiene que el fortalecimiento de los procesos de gobernabilidad y desarrollo participativo son necesarios para una reducción sostenida de la pobreza. A partir de ello, afirma que el aumento de la 'voz' de los pobres, por medio de la construcción de su capital social y el fortalecimiento

${ }^{6} \mathrm{La}$ Cepal entiende lo simbólico como lo inmaterial. Así habla de la pobreza simbólica para referirse a aquella que puede medirse en escasos años de escolaridad, desconocimiento respecto al uso de los nuevos medios de comunicación y falta total de acceso al poder y las decisiones públicas, y a las redes de promoción social y profesional (Cepal, 2000b). 
de su capacidad organizativa, promueve los cambios de política y el apoyo político necesario para reducir la pobreza. Según este organismo, el capital social contribuye a la construcción de economías competitivas, sistemas políticos democráticos y sociedades más solidarias, sin pobreza ni exclusión.

Por su parte, en su Informe sobre el Desarrollo Mundial 2000/ 2001, el вм privilegia una estrategia contra la pobreza centrada en el desarrollo humano sostenido, la movilización social y la potenciación de la gente, especialmente de aquella con menores recursos; respecto a lo último, afirma que las normas y redes sociales son una forma de patrimonio que puede ayudar considerablemente a los necesitados a salir de la pobreza.

De igual manera, el PNUD plantea en su Informe sobre desarrollo humano 2001 que las transformaciones tecnológicas actuales tienen enormes posibilidades de ayudar a erradicar la pobreza, pero reconoce que para eso es necesario construir capital social e incrementar las capacidades institucionales.

Si el desarrollo implica hoy capacidad para procesar información y conocimiento y aplicarlos a la mejora de la producción y de la calidad de vida, su producción efectiva exige disponer de la infraestructura de comunicación y del capital humano capaz de utilizarla. Nada de eso es posible sin construir el capital social y las capacidades institucionales necesarias al respecto (PNUD, 2001: 37).

Según Durston y Miranda (2001), en la tarea de determinar los aportes del capital social a la superación de la pobreza se mantienen al menos dos supuestos:

a) Que el capital social permite explorar y complejizar las dimensiones de la pobreza, enfatizando los mecanismos culturales que la reproducen y que la mitigan. Se destaca por ello el rol del capital social en tanto redes y normas sociales que permiten a los grupos movilizar y acumular activos que les permitan mantener posiciones de poder dentro de la estructura social (reproduciendo los niveles de pobreza ya existentes). Asimismo, permite a los desposeídos desarrollar estrategias que puedan mitigar los efectos de la pobreza mediante acciones colectivas que les posibiliten mayores niveles de participación y protagonismo en la solución de los problemas que enfrentan.

b) Que el capital social permite explorar y complejizar indicadores de pobreza que posibilitan el desarrollo de nuevas metodologías participativas, las cuales problematicen el rol del 
capital social en la reproducción y mitigación de la pobreza, al tiempo que su misma aplicación implique reforzar los niveles de capital social ya existentes.

Ambas líneas, según los autores citados, permiten analizar el fenómeno de la pobreza y de las acciones consensuadas entre el Estado y la sociedad civil, incluyendo factores de participación y fortalecimiento organizacional de los pobres.

Como puede verse, hoy día la noción de capital social ha cobrado especial relevancia en las discusiones y propuestas acerca del desarrollo y la superación de la pobreza, especialmente dentro de las políticas de los organismos internacionales, por lo que se constituyen en un paradigma vigente que se hace presente en todos los discursos, planes y programas de desarrollo actuales.

\section{Pobreza indígena y capital social}

Una vertiente del capital social, que consideramos ha sido poco explorada, es la que tiene que ver con los grupos indígenas de América Latina, particularmente si analizamos el concepto de capital social de acuerdo con el supuesto de sus aportes a la superación de la pobreza y la gobernabilidad democrática, pues hasta ahora los indígenas continúan siendo los más pobres entre los pobres; sufren de discriminación y exclusión social, y la violación a sus derechos humanos más elementales sigue siendo una constante.

La crítica y desigual situación de los pueblos indígenas tiene su origen en factores socioculturales y económicos de larga tradición histórica, donde la discriminación étnica juega un papel central como fuente de exclusión, pobreza y marginalidad (Álamo, 2003: 1).

En el proyecto moderno de constitución y formación del Estadonación, los pueblos indígenas quedaron simbólicamente integrados, pero excluidos en la práctica, pues su consideración en el proyecto de nación significó su sometimiento, en una lógica de barbarie y civilización. Fue así que el Estado asumió el rol de civilizador y orientó sus políticas a la asimilación e incorporación de los indígenas en los patrones de la sociedad nacional, lo cual ha significado para ellos, a lo largo de los años, el despojo de sus bienes simbólicos y materiales, el desconocimiento y la supresión de sus derechos colectivos y la negación de su cultura. 
Dos siglos de construcción de las naciones de Latinoamérica han estado marcados por la ausencia y, en muchos casos, por la oposición a lo indígena. La no aceptación a la diferencia ha sido la constante en los proyectos nacionales, aunque también se han presentado políticas indigenistas que protegen y multiplican la diferencia cultural a grados tan extremos que impiden la participación de lo indio en el Estadonación” (Sandoval, 2001: 23).

Los grupos indígenas de América Latina son descendientes de las extraordinarias civilizaciones prehispánicas, herederos de una vasta cultura ancestral que se truncó con el desembarco de los europeos en este continente.

La mayoría de los cálculos realizados coincide en señalar que en América Latina existen 40 millones de indígenas, lo que equivale a más de $10 \%$ del total de la población de la región. En el mismo sentido se menciona que existen alrededor de 400 grupos étnicos diferentes, cada uno de los cuales habla un idioma distinto, tiene cosmovisión y organización social distinta, así como distintas formas de organización económica y modos de producción adaptados a los ecosistemas que habitan.

Bolivia, Guatemala, Perú, Ecuador y México son los países en los que se concentra 90\% de los indígenas de la región, aunque la mayor proporción de dicho porcentaje se ubica en sólo dos de estos países: México y Perú. No obstante, hay que decir que en el caso de Bolivia, Guatemala, Perú y Ecuador, la población indígena representa entre 50 y $70 \%$ de la población total que habita en cada uno de esos países, lo que no ocurre para el caso de México, donde dicho sector representa poco más de 10\% de la población total.

En 1989, el convenio 169 sobre los pueblos indígenas de la Organización Internacional del Trabajo (OIT), definió a los indios como los descendientes de los habitantes originales de una región geográfica antes de la colonización y que han mantenido total o parcialmente sus características lingüísticas, culturales y de organización social.

En 1991, el Banco Mundial definió a los indígenas a partir del idioma, autoidentificación y área geográfica, así como de la presencia de costumbres sociales y de instituciones políticas propias, y de la existencia de una economía orientada a la subsistencia.

José Martínez Cobo se refiere a los pueblos indígenas como aquellas comunidades que se consideran diferentes de los restantes sectores de la sociedad y que se encuentran determinadas por el hecho de conservar, desarrollar y trasmitir a las genera- 
ciones futuras sus territorios ancestrales y su identidad étnica, considerados ambos como base de su existencia.

En nuestro entender, los pueblos indígenas son poblaciones que además de su propia lengua comparten un pasado histórico, territorio, valores, tradiciones, costumbres y, por supuesto, un gran sentido de pertenencia.

\subsection{Pobreza indígena}

"El común denominador de los pueblos indígenas de América Latina sigue siendo la pobreza, marginación, humillación y exclusión de los contextos nacionales e internacionales, ello se refleja también en la ausencia del poder indígena y en el no reconocimiento pleno de sus derechos, dentro de los marcos constitucionales y legales de cada país" (Sandoval, 2001: 45).

Los pueblos indígenas tienen los más altos niveles de analfabetismo, desnutrición, así como elevadas tasas de mortalidad infantil y de fecundidad. A menudo sufren discriminación, opresión y violaciones a sus derechos humanos por parte de los sectores no indígenas y de los propios gobiernos, al grado que podría decirse que hoy día representan uno de los grupos sociales que mayor represión ha sufrido por parte de las fuerzas de los Estados. Entre las violaciones más comunes a sus derechos podemos contar, entre otras, el despojo e invasión de sus tierras comunales; la persecución a sus organizaciones tradicionales, sociales y políticas; el no reconocimiento a sus culturas; el desprecio por sus idiomas; la no aceptación y la sanción a sus sistemas culturales-jurídicos; el diseño y aplicación de políticas públicas dirigidas a exterminar a la población indígena; la prohibición de prácticas de medicina tradicional, y la aplicación de juicios en tribunales exclusivos en idioma español, sin traductores y sin peritajes antropológicos que contextúen los delitos cometidos por los indígenas.

De tal modo, sostenemos que la pobreza indígena es una pobreza condicionada por múltiples formas de exclusión. Se trata de una pobreza no sólo de orden material sino también y, si acaso más, de orden simbólico; es un tipo de pobreza que puede medirse por los escasos años de escolaridad, los elevados niveles de desnutrición, la falta de información y acceso a los medios de comunicación, y la falta de acceso al poder, a las decisiones públicas y a la promoción social y profesional. Dicho de otro modo, las causas fundamentales de la pobreza indígena están enraizadas en las rela- 
ciones sociales y económicas desiguales que ocurren entre la población indígena y los sectores no indígenas de la sociedad.

Conforme a lo anterior, podemos afirmar que existe una alta correlación entre la pertenencia a un grupo indígena y los elevados niveles de pobreza. Uno de los ejemplos más claros se encuentra en los municipios mexicanos, donde los niveles de pobreza son casi cuatro veces más elevados en aquellos de mayor población indígena (con niveles de casi $80 \%$ ) que en los que no tienen ese tipo de población, mientras que los niveles de pobreza extrema son 20 veces más elevados (40\%). En Bolivia, más de la mitad de la población total se encuentra en situación de pobreza; en Guatemala, casi dos tercios de la población sufre de esa situación; en Perú, el nivel de pobreza es de 79\% entre indígenas y de 49.7\% entre no indígenas (Álamo, 2003).

Sin embargo, a pesar de que se construyen Estados-nación con políticas de discriminación y desigualdad sociocultural de una nacionalidad dominante sobre los grupos étnicos -y la persistencia de este hecho en el contexto actual-, los indios han sobrevivido. Ello se debe a que los pueblos indígenas han ofrecido resistencia, la que se ha estructurado a partir de sus organizaciones, normas comunales, costumbres, cultura e identidad, que reflejan un potencial rico para la promoción y fortalecimiento del capital social.

\subsection{Capital social indígena}

El mundo de los indígenas sigue guiándose por principios de tipo colectivo, ritual y espiritual, en oposición al mundo moderno, que promueve el individualismo, la secularización y la materialización a partir de los bienes y el dinero. La economía indígena está fundada en las relaciones sociales y se caracteriza más por las nociones de reciprocidad que por los valores de mercado. De la misma manera, la organización social tradicional se basa en el parentesco, es de carácter informal y no se ha desarrollado en respuesta a las demandas de la economía de mercado.

Para mostrar estos aspectos, nos remitimos a las investigaciones que hemos desarrollado en el Estado de México sobre los grupos indígenas, particularmente sobre los mazahuas (la etnia más numerosa en la entidad).

El Estado de México es la entidad más poblada del país; en el año 2000, según el Censo de Población, tenía un total de 13’083,359 habitantes distribuidos en 124 municipios. 
Se trata de una entidad caracterizada por su diversidad social, política, cultural y étnica. En su territorio podemos encontrar municipios altamente industrializados y urbanizados, en los que se concentra un alto porcentaje de la población. Pero también pueden observarse municipios semiurbanizados y rurales con grados altos de marginación y pobreza; en estos últimos se localiza una gran parte de la población indígena de la entidad.

La resistencia cultural de los indígenas entrelaza lo tradicional con lo moderno en todos los ámbitos de la vida cotidiana. Sus estrategias de supervivencia han estado fincadas en la organización social tradicional, en la adaptación de algunos elementos no indios, en la relación permanente con su territorio, en la adscripción a su grupo étnico y, por supuesto, en la reactivación de los componentes culturales más interiorizados y expresados por su población.

La eficacia ha consistido en cambiar, adaptar y mantener sus formas de vida, producción, relación con la naturaleza y organización social. Al mismo tiempo, la capacidad de adaptación les ha impuesto costos culturales, sociales, familiares y comunitarios; pero también esa versatilidad en la incorporación de lo ajeno y en la conservación de elementos determinantes de la cultura les ha posibilitado vivir en medio de las adversidades (Sandoval, 2001:86).

Es importante tener en cuenta que los indios de hoy no son sólo agricultores, también son obreros, comerciantes, albañiles, artesanos, migrantes definitivos o temporales, vendedores ambulantes, prestadoras de servicios domésticos y, en menor medida, profesionales. En estos procesos de transformación social, algunos abandonan la identidad étnica, y en otros ésta se transforma; en otros casos intentan reconstruir su condición india en su nuevo entorno formando organizaciones que reivindiquen su cultura, necesidades materiales y derechos a participar.

La etnia mazahua conforma una etnorregión por sus aspectos de identificación colectiva de indígenas contemporáneos, sin perder de vista su devenir histórico, pero sí remarcando los actuales contextos económicos y sociales que los obligan a readecuar la percepción del mundo, así como su vivencia en él. La adaptación y resistencia de los mazahuas se ha conformado a partir del sistema de organización tradicional, y en particular a partir del sistema de cargos, que les ha servido para defender sus derechos como grupo y desarrollar una fuerza cohesionadora intracomunitaria.

Las relaciones sociales de los mazahuas en la cooperación y el trabajo mutuo, cuyo control se ejerce principalmente por el sistema de cargos, apuntan a la participación igualitaria de todos 
los integrantes de la comunidad. De esta forma, la identidad de los actuales mazahuas se forja en sus prácticas culturales colectivas, que de manera permanente se repiten y reacondicionan en tres ámbitos de la cotidianidad indígena: la etnorregión, los ciclos y ritos agrícolas, y las festividades mítico-religiosas.

Los espacios utilizados para las festividades indígenas son siempre públicos: el patio de la iglesia, las canchas deportivas, el tianguis, las calles, el cementerio y los parques. Las procesiones, la presencia masiva de la población y las cuadrillas de danzantes son los aglutinadores y la expresión de la sociabilidad mazahua, con todo y sus sentimientos de pertenencia a los objetos y sujetos ceremoniales.

Estas prácticas de sociabilidad en espacios públicos dan continuidad no sólo a las tradiciones culturales y religiosas de las comunidades, sino también al sistema de organización tradicional y a su constante lucha por preservar espacios que les son inherentes a su pasado y presente indígena.

La vida cotidiana de los mazahuas se encuentra intensamente relacionada con la vida natural: tierra, siembra, cuidado y cosecha con todos sus ritos y fiestas en los diversos ciclos. A partir de esto se generan códigos y lazos sociales que le dan cohesión al grupo. Igual sucede con los diferentes periodos de la vida, cuyas expresiones en rituales y símbolos estructuran vínculos afectivos familiares y sociales que, junto con elementos del entorno como el espacio, ordenan la vida individual y social.

Sin duda alguna, la primera instancia de socialización de la cultura y de relaciones de autoridad se genera en el grupo doméstico; ahí, el niño o niña aprende la lengua indígena asociada a un conjunto de normas culturales y ciertas pautas de comportamiento referidas a los roles de edad, sexo y autoridad que, posteriormente, se desplazan al ámbito comunitario. Así, el grupo doméstico junto con todas sus estructuras de parentesco ampliado son los que inducen a los descendientes a colaborar en su sociedad interiorizando valores culturales que, incluso, se oponen a los que imparten las instituciones que representan a la sociedad nacional, como la escuela, la Iglesia y los partidos políticos.

Podemos asegurar que el sistema de organización comunitaria compensa la inestabilidad de los miembros del grupo doméstico y las influencias de la cultura occidental, pues genera una gran cohesión social, definida por las diversas redes sociales, culturales y religiosas que se entretejen en cada comunidad y que incluso se trasladan a otros espacios como las ciudades, donde 
los migrantes tienden a la conformación de redes de asistencia, cooperación y ayuda mutua para sobrevivir en un espacio donde son explotados, marginados, humillados y discriminados.

No obstante, podemos afirmar que la existencia de estos elementos, por sí sola, no constituye capital social, pues si bien dichas prácticas generan la participación en la consecución de objetivos colectivos, no contribuyen al beneficio, porque en el contexto nacional los indígenas mantienen su posición de subordinación con el poder político. Es decir, sus prácticas les han permitido refuncionalizar su cultura y sobrevivir en un mundo ajeno, pero no los conducen a superar sus situaciones de pobreza, exclusión y marginalidad.

En todos los casos, la autoridad y el control interno de la comunidad, o más precisamente la gobernabilidad intracomunitaria, tienen una doble función: la reproducción cultural y el control social indígena, por una parte; y, por otra, la legitimación de la sujeción y dominación de la población indígena al poder de los no indios (Sandoval, 2001: 106).

A esto se suma la tendencia de desestructuración que están sufriendo las comunidades indígenas por varios factores, como la introducción de grupos religiosos no católicos en sus comunidades, el aumento de la migración y el desplazamiento por la violencia que ejerce, de forma legítima, el Estado.

\section{Capital social indígena y desarrollo local: algunas limitantes}

El contexto signado por nuevas amenazas a la sostenibilidad del desarrollo humano ha obligado a reconsiderar la importancia de la gestión local ante la emergencia de desafíos que trascienden su papel tradicional, a fin de promover las oportunidades de desarrollo de la gobernabilidad y la participación comunitaria.

El término desarrollo local es utilizado y entendido, a menudo, de forma ambigua, lo cual obliga a un esfuerzo previo de conceptuación con el fin de precisar su utilidad en la práctica. A veces por desarrollo local se entiende exclusivamente el desarrollo de un ámbito territorial inferior, como puede ser el desarrollo de un municipio; otras veces se utiliza para resaltar el tipo de desarrollo endógeno que es resultado del aprovechamiento de los recursos locales de un determinado territorio. En otras ocasiones hay quien lo presenta como una forma alternativa al tipo de desarrollo concentrador y excluyente predominante, que se basa esencialmente en un enfoque vertical en la toma de decisiones. 
Para nosotros, el enfoque del desarrollo local toma como unidad de actuación principal al territorio o ámbito de una determinada comunidad; se basa en la movilización y participación de los actores territoriales públicos y privados como protagonistas de las iniciativas y estrategias de desarrollo local; se refiere a territorios y actores reales, no sólo a tendencias generales que ayudan poco al diseño de políticas de actuación en los diferentes ámbitos territoriales; y supone el abandono de las actitudes pasivas, ya que se basa en la convicción del esfuerzo y decisión propios para establecer y concertar localmente la estrategia de desarrollo.

El tema indígena también ha recuperado importancia en las discusiones recientes sobre el desarrollo. Durante las últimas dos décadas ha habido cambios importantes en los enfoques relativos a la identidad y los derechos indígenas. En el ámbito internacional existen cambios que incluyen nuevos y evolucionados estándares internacionales y un nuevo interés en el proceso.

En América Latina, el problema indígena toma dimensiones especiales, entre otras razones por el hecho de que la mayoría de sus países presenta la más grande diversidad étnica del mundo, y porque, históricamente, las etnias tienen una larga tradición de lucha. Los movimientos indios en América Latina han dejado claro que el derecho dominante, como instrumento normativo para la convivencia social, está rebasado por la realidad actual, pues el modelo de nación y la concepción de Estado que originaron las constituciones políticas de América Latina ya no corresponde a los tiempos de hoy, cuando las sociedades reclaman pluralismo, democracia, participación social y política, justicia y respeto a los derechos humanos.

En la década de los ochenta, los indígenas estuvieron presentes de manera importante en movimientos armados; los casos más significativos fueron Colombia, Guatemala y El Salvador. A principios de la década de los noventa, la movilización y las luchas indias en el continente se centraron en el reconocimiento de sus culturas, de sus tierras y en general de sus derechos como pueblos. En los primeros años del presente siglo hemos podido ver la persistencia de esta lucha con el incremento de organizaciones indígenas.

Teniendo en cuenta la vigencia que cobra el tema del desarrollo local y el problema indígena, los planteamientos actuales provenientes, en su mayoría, de organismos internacionales- se han orientado a la búsqueda de la solución de los problemas de pobreza y exclusión indígena, a la promoción del capital social y 
al "empoderamiento" de los indígenas para hacerlos partícipes de su propio desarrollo.

Frente a ello, las estrategias se orientan a promover y fortalecer el capital social de estos grupos, lo que lleva a reflexionar en distintos sentidos sobre la efectividad de tales planteamientos en el ámbito de las comunidades indígenas, sobre todo si consideramos el papel del Estado, pues muchas veces éste, en lugar de promover el capital social, tiende a su desestructuración.

Algunas reflexiones se sintetizan en los siguientes puntos que presentamos como limitantes para el capital social indígena y el desarrollo de las comunidades.

\subsection{Con relación al empoderamiento}

Si el empoderamiento significa la expansión de la libertad de elección y acción, y, por ende, el ejercicio pleno de los derechos humanos, consideramos que en la población indígena éste encuentra limitaciones por los siguientes aspectos:

a) Hay países en los que el Estado sigue implicado directamente en las violaciones de derechos humanos de los indígenas. En México este caso es muy representativo con los sucesos de violencia que han estado ocurriendo en Chiapas y otros en poblaciones indígenas de Oaxaca y Guerrero.

b) Asimismo, estamos en una época en la que si bien los avances tecnológicos e informáticos evolucionan día con día, todavía hay muchos derechos humanos elementales que no se cumplen cabalmente para una gran mayoría de la población, como el derecho a la salud, educación, alimentación y vivienda, por lo que resulta paradójico pensar que pueda ejercerse plenamente la ciudadanía.

c) En el sistema actual no hay organismos representativos de las comunidades dedicados a hacer valer las normas o a aplicar sanciones que se relacionen con lo social, económico, político, de orden civil o público. Los seudoconsejos supremos instaurados en el Estado de México, con supuesta representación, han sido controlados y puestos al servicio de los partidos políticos: Partido Revolucionario Institucional, Partido Acción Nacional y Partido de la Revolución Democrática, por lo que se han convertido en verdaderos instrumentos dóciles e interlocutores de éstos y no de los indígenas. 
d) Muchas organizaciones indígenas -que han tenido como fundamento una supuesta representación y participación de los indígenas en los asuntos del Estado- se desarrollaron de manera vertical: comenzaron como consejos de consulta nacional y sólo después establecieron presencia en el ámbito local. Como consecuencia, tales organizaciones han sido normalmente más exitosas en lograr objetivos políticos que en conseguir desarrollo social o económico comunitario. En México es muy clara su utilización con fines clientelares. La manipulación, el acarreo, el soborno, la desmovilización, y todas las prácticas características de la antidemocracia son el mejor acicate de los partidos políticos.

e) De la misma manera, las organizaciones indígenas actuales están siendo representadas por indígenas profesionales, lo que hace suponer que habría una mayor posibilidad para que éstas sean representativas en el contexto nacional y puedan interactuar en planos de igualdad. Sin embargo, lo que puede verse es la actitud prepotente de líderes que lucran con los intereses y necesidades de los demás indios, y obtienen recursos de instituciones y organismos internacionales.

Los pobres son quienes menos han podido incidir en las políticas, programas y proyectos que los afectan, pues su participación enfrenta fuertes limitaciones debido a la exclusión que también sufren; si a esto sumamos que los pobres están representados por la totalidad de los grupos indígenas, el asunto es más grave por la discriminación que enfrentan y por el status inferior que ocupan sus derechos respecto de los derechos universalmente reconocidos.

Si el empoderamiento se logra con el cumplimiento de los derechos y el ejercicio pleno de la ciudadanía, vemos entonces que aún quedan muchos vacíos para lograr tales condiciones. La participación social sigue siendo sólo parte de los discursos políticos y la gobernabilidad democrática es aún asunto pendiente.

\subsection{Con relación al fortalecimiento del capital social}

En lo que atañe al fortalecimiento del capital social, encontramos una cantidad de contradicciones.

a) Los organismos estatales encargados de atender al sector indígena y de orientar políticas públicas para la promoción de su desarrollo no han tenido más práctica que la del control 
social y político de los pueblos indígenas, lo que ha dado como resultado una atomización política de la organización indígena independiente y la carencia de participación étnica propia (en México, el Instituto Nacional Indigenista, por ejemplo).

b) Las políticas actuales que se orientan a los grupos indígenas mediante la ejecución de los programas como el Programa Nacional de Solidaridad, el Programa de Educación, Salud y Alimentación, y actualmente Oportunidades, en México, son estrictamente asistencialistas y poco o nada promueven la participación social.

c) La focalización de recursos y programas ha contribuido en parte a desestructurar comunidades, pues la selección de beneficiarios excluye a familias que las comunidades consideran que deberían recibir el apoyo. Las comunidades indígenas tienen un sistema de redistribución igualitaria por diferentes mecanismos de control social, y este hecho está generando alteraciones en el orden interno (Nahmad et al., 1998: 106).

d) Los grandes proyectos de desarrollo (como el Plan PueblaPanamá) tienen muchas veces consecuencias negativas para las poblaciones indígenas en tanto que devastan su entorno y llevan también a la desestructuración de las comunidades. La relación de los indígenas con la tierra tiene un significado que no sólo se reduce a factores de carácter económico-productivo, sino que se trata de un vínculo que conjuga aspectos sociales, culturales, espirituales, religiosos y económicos.

Existen también dificultades para el fortalecimiento del capital social, lo que se atribuye a la creciente desconfianza de los ciudadanos hacia la efectividad de las instituciones democráticas.

El papel del Estado, según los postulados del capital social y su contribución al desarrollo, debe ser promover y fortalecer el capital social, pero esto ha quedado en el discurso, pues en la práctica poco se ha avanzado para lograr una verdadera participación de la población indígena. Lo que puede verse, entonces, es una tendencia a generar capital social desigual.

\subsection{Con relación al fortalecimiento local}

Uno de los argumentos más recurrentes para justificar la importancia de lo local se refiere a que éste constituye el espacio más propicio para la participación social en la toma de decisones. No 
obstante, encontramos también varias contradicciones, especialmente cuando se trata de poblaciones indígenas.

a) La racionalidad para la exclusión es quizá más crudamente expresada en el nivel local, donde las autoridades municipales o las agencias locales omiten las necesidades de los indígenas o se rehúsan a trabajar con ellos con el argumento de que son ignorantes y atrasados.

b) Los pueblos indígenas han sido tradicionalmente excluidos de los procesos políticos y esto ha limitado su capacidad de gestionar recursos. Sufren una desventaja doble, como población rural y como grupos étnicos diferenciados con sus intereses a menudo representados por organismos no gubernamentales.

c) La capacidad institucional en el ámbito local es crítica para alcanzar un desarrollo económico y social sostenible. Los procesos de capacitación y fortalecimiento institucional, más que los ingresos o la provisión de servicios, constituyen la esencia del desarrollo de base, ya que eso posibilita a los indígenas tratar con otros sectores de la sociedad en términos de igualdad. Sin embargo, podemos observar que en las comunidades indígenas mexicanas es evidente la ausencia de capacitación de todas sus instituciones, por lo que su actuación e interacción con otros miembros de la sociedad continúa siendo total asimetría.

d) En el ámbito de la gestión, se hace poco uso de técnicas y métodos para identificar el capital social disponible antes de la formulación y evaluación de proyectos. En México, en muchos municipios rurales sigue utilizándose el modelo de planeación tradicional y no el de la planeación estratégica, que supone los principios de la Nueva Gestión Pública.

e) En el plano político, la comunidad desempeña un papel dependiente de los poderes locales, de la penetración de los partidos políticos, de los cacicazgos, de la lucha de clases y de la manera en que la problemática regional, estatal y nacional incide en cada una de las poblaciones.

Aunque existen experiencias relativamente exitosas de gestión local alternativa, cabe destacar que hay limitantes importantes para reproducirlas en otros contextos, en lo referente a su capacidad de impulsar el desarrollo local, pues no todas las localidades están en condiciones de enfrentar ese reto.

Aunado a todo lo anterior, encontramos que a los tradicionales problemas de baja integración social como son la pobreza, la 
discriminación étnica y la segmentación social, entre otros, se agregan ahora nuevos fenómenos entre los que predominan la violencia, la inseguridad ciudadana, el narcotráfico y la corrupción, con lo cual se debilitan, o incluso se anulan los lazos de pertenencia y el ejercicio de una ciudadanía efectiva, lo que viene a cuestionar la tan citada democracia.

\section{Conclusiones}

Si bien actualmente el concepto de capital social tiene relevancia para una nueva conceptuación de las políticas públicas, por sus implicaciones para una mayor participación de la sociedad civil y la democratización, también es cierto que enfrenta todavía diversos obstáculos y limitantes que hacen cuestionables los efectos que se le atribuyen en relación con el logro de la equidad, la igualdad, la democracia y la superación de la pobreza, particularmente cuando se traslada al espacio indígena.

Sin lugar a duda, desde la mitad de la década pasada se ha producido un cambio marcado en la retórica de los organismos internacionales, al introducir en sus programas la noción de pobreza asociada con la cuestión étnica. Sin embargo, existe aún un abismo entre la retórica y la realidad, pues no ha habido reformas serias y profundas para lograr las condiciones en que sea posible el funcionamiento del capital social como fuente de desarrollo.

En tanto, la globalización continúa su camino ascendente, contradictorio, antidemocrático y desventajoso, que afecta principalmente a los países pobres. Frente a esto, cabe preguntarse si es posible hablar de sociedades con alto sentido de pertenencia, cohesión y solidaridad, cuando lo que estamos viviendo en nuestras regiones es una fragmentación social generada por la pobreza, la exclusión, la inseguridad, la constante violación de los derechos humanos y la corrupción de quienes han tenido en sus manos el destino de nuestros países.

Respecto a la población indígena, el capital social, su desarrollo y fortalecimiento presenta desniveles propios de las condiciones sociales, culturales y de etnicidad de cada grupo indígena. En términos generales, el capital social es abundante, aglutinador y con fortalezas que hacen que sea posible potenciarlo a partir del respeto de sus organizaciones tradicionales. La cohesión social es una de las mayores virtudes del capital social de los indígenas, y su extensión se presenta hasta con la población que ha migrado a las grandes ciudades de México o Estado Unidos. Diversas son 
las redes de migrantes, y también la aportación del capital social y económico de esta población ha contribuido a que se fortalezcan los lazos de solidaridad y de comunitarismo en las localidades indígenas.

\section{Bibliografía}

Álamo, Óscar del (2003), El lado indígena de la desigualdad, documento presentado en la Conferencia Internacional Democracia, Gobernanza y Bienestar en las Sociedades Globales, 27-29 de noviembre de 2003, Barcelona.

BID (Banco Interamericano de Desarrollo) (2001), Iniciativa interamericana de capital social, ética y desarrollo, http:// wwwiadb.org/etica/iniciativa.cfm.

Banco Mundial (1990), Informe sobre el desarrollo mundial, Banco Mundial, Washington, DC.

(2001a) ¿Qué es el capital social?, http://www.worldbank. org/poverty/spanish/scapital/index.htm, agosto de 2001.

(2001b), Informe sobre el desarrollo mundial 2000/2001. Lucha contra la pobreza, Panorama General, Washington, DC.

Baquero, Marcello (2001), Reinventando a sociedade na América Latina: Cultura política, gênero, exclusão e capital social, Ufrs-Conshelho Nacional dos Direitos da Mulher (CNDM), Porto Alegre-Brasilia.

Bourdieu, Pierre (1983), “The Forms of Capital”, en John G. Richardson (ed.), Handbook of Theory and Research for the Sociology of Education, Greenwood Press, NY, Westport, CT, pp. 241-258.

Cepal (Comisión Económica para América Latina y el Caribe) (2000a), Equidad, desarrollo y ciudadanía, Cepal, Santiago de Chile.

(2000b), Panorama social de América Latina, 1999-2000, Cepal, Santiago de Chile. 
(2001), Perspectivas de América Latina en el nuevo contexto internacional, http: //www.cepal.org, 22 de mayo de 2003.

Coleman, James (1990), Foundations of Social Theory, Belknap Press, Cambridge, Mass.

Durston, John (2000), ¿Qué es el capital social comunitario?, Cepal, Serie Políticas Sociales núm. 38, Santiago de Chile.

(2002), El capital social campesino en la gestión del desarrollo rural, Naciones Unidas-Cepal, Santiago de Chile.

y Francisca Miranda (comps.) (2001), Capital social y políticas públicas en Chile, vol. I, Cepal, Serie Políticas Sociales núm. 55, Santiago de Chile.

Firth, Raymond (1961), Elements of Social Organization, $3^{\text {a }}$ ed., Beacon Press, Boston, Mass.

Foster, George (1961), “The Dyadic Contract: A Model for the Social Structure of a Mexican Peasant Village", American Anthropologist, Washington, DC, 63 (6): 1173-1192.

Fukuyama, Francis (2000), A grande rupture, trad. Nivaldo Mantingelli, Rocco, Río de Janeiro.

Granovetter, Mark S. (1985), "Economic Action and Social Structure: The Problem of Embeddedness", American Journal of Sociology, noviembre, 91 (3): 481-510.

Grootaert, Christiaan y Thierry van Bastelaer (2001), Understanding and Measuring Social Capital: A Synthesis of Findings and Recommendations from the Social Capital Initiative, The Social Capital Initiative World Bank, working paper 24, the World Bank, Washington, DC.

Hopenhayn, Martín (2001), "Viejas y nuevas formas de la ciudadanía”, Revista de la Cepal, Santiago de Chile, 73: 117-128.

Kliksberg, Bernardo y Luciano Tomassini (comps.) (2000), Capital social y cultura: claves estratégicas para el desarrollo, 
Banco Interamericano de Desarrollo-Fundación Felipe Herrera-Universidad de Maryland-Fondo de Cultura Económica, Buenos Aires.

Knack, Stephen y Philip Keefer (1997), “Does Social Capital Have an Economic Payoff? A Cross-Country Investigation", The Quarterly Journal of Economics, 112 (4): 1251-1288.

Molinas, José R. (2002), Innovaciones en la politica social: el papel del capital social, http://www.paraguayglobal.com/ investigaciones.php, 25 de marzo de 2004.

Mota Díaz, Laura (2002), "El capital social: un paradigma en el actual debate sobre el desarrollo. Tendencias y problemas", Espiral, estudios sobre Estado y sociedad, Universidad de Guadalajara, México, septiembre-diciembre, IX (25): 37-65.

Nahmad, Salomón, Tania Carrasco y Sergio Sarmiento (1998), "Acercamiento etnográfico y cultural sobre el impacto del Programa Progresa en doce comunidades de seis estados de la República”, en varios, Alivio a la pobreza, análisis del Programa de Educación, Salud y Alimentación dentro de la política social, Centro de Investigaciones y Estudios Superiores en Antropología Social-Progresa, México, pp. 62-113.

Narayan, Deepa (1999), Bonds and Bridges: Social Capital and Poverty, Banco Mundial, Washington, DC.

North, Douglass C. (1990), Instituciones, cambio institucional y desempeño económico, Fondo de Cultura Económica, México.

Ostrom, Elinor y Tae Kyu Ahn (2003), "Una perspectiva del capital social desde las ciencias sociales: capital social y acción colectiva", Revista Mexicana de Sociología, Instituto de Investigaciones Sociales, Universidad Nacional Autónoma de México, enero-marzo, LXv (1): 155-233. 
PNUD (Programa de Naciones Unidas para el Desarrollo) (2001), Informe sobre desarrollo humano 2001, http:// www.undp.org/hdr2001/spanish/, diciembre.

Informe sobre desarrollo bumano 1998, PNUD, Nueva York.

Informe sobre desarrollo humano 1997, PNUD, Nueva York.

Portes, Alejandro y Patricia Landolt (1996), "The Downside of Social Capital”, The American Prospect 26, http://epn.org/ prospect/26/26-cnt2.

Putnam, Robert D. (1993), “The Prosperous Community: Social Capital and Public Life", The American Prospect 13, http:/ /epn.org/prospect/13/13 putn.htlm.

Sandoval Forero, Eduardo A. (2001), La ley de las costumbres en los indígenas mazahuas, Universidad Autónoma del Estado de México, México.

Spicker, Paul (1999), Poverty and Social Security, Routlegde, Londres.

Stein, Rosa Helena (2003), Capital social, desarrollo y políticas públicas en la realidad latinoamericana, documento de trabajo 03-05, Unidad de Políticas Comparadas, Consejo Superior de Investigaciones Científicas (CSIC), Madrid.

Toledo, Fernando C. (2004), "Capital social, desarrollo y reducción de la pobreza. Hacia un debate multidisciplinario que contemple eje de discusión relevantes", en Laura Mota Díaz y Antonio D. Cattani (coords.), Desigualdad, pobreza, exclusión y vulnerabilidad en América Latina. Nuevas Perspectivas analiticas, Facultad de Ciencias Políticas y Administración Pública de la Universidad Autónoma del Estado de México-Centro de Estudios sobre Marginación y Pobreza del Estado de México-Universidad Federal de Río Grande del Sur-Asociación Latinoamericana de Sociología, Toluca, México.

UNESCO (Organización de las Naciones Unidas para la Educación, la Ciencia y la Cultura) (2001), La erradicación de la pobreza: 
implicaciones de la cooperación para el desarrollo, http:// www.unesco.org/issj/rics162/snortspa.htm, 16 de marzo.

Recibido: 27 de junio de 2005. Aceptado: 9 de septiembre de 2005.

Laura Mota Díaz es maestra en ciencias sociales con especialidad en desarrollo municipal por El Colegio Mexiquense A.C. y candidata a doctora en ciencias políticas y sociales con orientación en administración pública por la Facultad de Ciencias Políticas y Sociales de la UNAM. Como líneas de investigación maneja la pobreza, las políticas públicas y el desarrollo local. Son sus últimas publicaciones: "As faces atuais da pobreza urbana: elementos para uma reorientacão da política social”, en Antonio David Cattani y Laura Mota Díaz (coords.), Desigualdades na América Latina. Novas perspectivas analíticas, Editora UFRGS, Porto Alegre, 2005, pp. 73-89; "Los rostros actuales de la pobreza urbana: elementos para una reorientación de la política social”, en Laura Mota Díaz y Antonio David Cattani (coords.), Desigualdad, pobreza, exclusión y vulnerabilidad en América Latina. Nuevas perspectivas analíticas, FCPYAP, UAEM-CEMAPEM-UFRGS-ALAS, México, 2004, pp. 81-100; "Administración y políticas de educación superior en México. Logros y dificultades para la vinculación investigación-posgrado”, en Laura Mota Díaz y José Luis Cisneros (coords.), La educación superior en América Latina, globalización, exclusión y pobreza, Universidad Autónoma Metropolitana, unidad Xochimilco-Insumisos Latinoamericanos-Libros en Red, Buenos Aires, 2004, pp. 395-429; y "Urbanización y gobierno local: los desafíos municipales en la era global", en Desarrollo Local en un mundo Global, de autores varios, Universidad de Málaga, España, 2004 (versión electrónica en CD).

Eduardo Andrés Sandoval Forero obtuvo el grado de doctor en sociología por la Facultad de Ciencias Políticas y Sociales de la UNAM, y es investigador nacional nivel II. Su línea de investigación se centra en las culturas indígenas. Entre sus publicaciones sobresalen: Cultura y organización social en los indígenas mexiquenses, Universidad Autónoma del Estado de México-Unidad de Apoyo Académico a Estudiantes Indígenas-Fundación FordANUIES, México, 2005; el CD multimedia Presencia indígena en el Estado de México, Universidad Autónoma del Estado de México- 
Unidad de Apoyo Académico a Estudiantes Indígenas-Fundación Ford-Anuies, México, 2005; La Danza de los Arrieros: entre la identidad y la memoria, ediciones Insumisos Latinoamericanos, México, 2004; y El temazcal otomí. Ritual de purificación, sanación y refrescamiento, Universidad Autónoma Indígena de México-Uaeméx, México, 2003. 